\title{
UMA ANÁLISE DO LEVIATHAN ENQUANTO METÁFORA E REPRESENTAÇÃO
}

\author{
An analysis of Leviathan as metaphor and representation
}

Mateus Matos Tormin *

Resumo: Este pequeno artigo está divido em quatro seções. Na primeira, retomo trechos do livro The elements of representation in Hobbes, de Mónica Vieira, com o intuito de introduzir nosso tema: o Leviatã enquanto metáfora e representação. Ressalto a importância, resgatada por Vieira, do elemento estético da teoria da representação em Hobbes, e retomo trechos em que a autora analisa a metáfora e seu uso em Hobbes. Concluo essa primeira seção com uma citação que é, ao mesmo tempo, um convite para examinarmos o Leviatã enquanto metáfora. Nas seções 2 e 3, aceito esse convite e procedo a uma inspeção da metáfora. Em um primeiro momento (seção 2), procuro reconstruí-la conforme apresentada por Hobbes já no primeiro parágrafo de seu livro; ao fazer isso, busco também analisála, tentando explicitar os significados sugeridos pelo texto hobbesiano. Em um segundo momento (seção 3), com base em um ensaio de Carlo Ginzburg, levo o exame da metáfora adiante ao explorar a questão da semelhança entre o Leviatã e a religião - ressaltando a centralidade do medo enquanto paixão na explicação tanto do fenômeno religioso, quanto do político. Na quarta e última seção, retomo o percurso brevemente.

Palavras-chave: Leviatã, Metáfora, Representação, Estado, Religião.

\begin{abstract}
This short article is divided in four sections. In the first section, I make reference to excerpts from Monica Vieira's book The elements of representation in Hobbes. By doing that, I introduce the main theme of this article: the figure of Leviathan as a metaphor and representation. I then highlight the importance of the aesthetic element in Hobbes' theory of representation, and mention excerpts in which Vieira examines the metaphor and its use in Hobbes. I conclude this first section with a quote which is a sort of an invitation to a close inspection of Leviathan as a metaphor. In sections 2 and 3, I accept this invitation and proceed to an inspection of the metaphor. In section 2, I reconstruct it as it was presented by Hobbes in the first chapter of his book (Leviathan), while also trying to bring to light the implicit meanings suggested by Hobbes' text. In section 3 , I continue the inspection by exploring the similitude between Leviathan and religion. Based on an essay written by Carlo Ginzburg, I try to highlight the importance of "fear" as a passion in the account of both the religious and the political phenomena. In the fourth and concluding section, I briefly recapitulate the main threads of the article.
\end{abstract}

Keywords: Leviathan, Metaphor, Representation, State, Religion.

* Mestrando em Teoria e Filosofia Política no PPG do DCP-USP e aluno no PG de Filosofia da mesma instituição. Bolsista do CNPq. E-mail: mateusmmt@gmail.com.

\begin{tabular}{|c|c|l|l|c|c|}
\hline intuitio & $\begin{array}{c}\text { ISSN } \\
1983-4012\end{array}$ & Porto Alegre & Vol.11 $-\mathrm{N}^{\mathrm{o} .2}$ & $\begin{array}{c}\text { Dezembro } \\
2018\end{array}$ & p.34-46 \\
\hline
\end{tabular}




\section{Introdução - Leviathan, a metaphor inviting inspection}

\section{$[P]$ olitical reality is actually created or constituted by modes of representation ${ }^{1}$.}

Mónica Vieira introduz seu livro The elements of representation in Hobbes chamando a atenção para uma interpretação influente e equivocada da teoria da representação de Hobbes, segundo a qual esta seria estritamente política. Para Vieira, essa interpretação se equivoca ao desconsiderar a centralidade da representação dentro das artes visuais. Em oposição a essa interpretação (associada à influência da análise de Hanna Pitkin), Vieira apresenta a posição que pretende defender: a noção de representação em Hobbes não tem apenas o sentido de agência (no sentido de agir por algo ou alguém - i.e., ser um representante de algo ou alguém), mas também o sentido de descrição metafórica ou simbólica (no sentido de estar no lugar de algo ou alguém (standing for) - i.e., oferecer uma representação de algo ou alguém). Para Vieira, ambos os sentidos podem ser eficazmente empregados em afirmações políticas relativas à representação. Ela exemplifica mencionando precisamente o Leviathan: Vieira chama a atenção para o componente estético da metáfora que introduz o Estado (Commonwealth) já no primeiro parágrafo do livro. Conforme veremos, o Leviathan ou o "homem artificial" é apresentado como um trabalho artístico-artesanal (artwork) do homem que imita ou mimetiza a natureza (definida por Hobbes como a arte divina). Além disso, a mesma imagem é também uma metáfora impactante que nos permite ver o Estado como fruto da representação política ${ }^{2}$.

A importância do elemento estético pode ser sintetizada na seguinte máxima: ver é crer. Vieira ressalta essa frase, dizendo que, para Hobbes, as imagens não são representações passivas do representado; ao contrário, são ativas, já que não só representam o representado, mas também o moldam, construindo-o. Nesse sentido, a arte de representar é também ação - e de um tipo bastante eficaz, na medida em que age diretamente na imaginação e, consequentemente, nas paixões (um dos catalisadores mais eficazes do comportamento humano). A própria imagem do Leviatã, à qual Hobbes recorre, ilustra bem este ponto:

\footnotetext{
${ }^{1}$ VIEIRA, M. B. The elements of representation in Hobbes: Aesthetics, theatre, law and theology in the construction of Hobbes's theory of State. Leiden \& Boston: Brill, 2009, Introductory Note.

${ }^{2}$ VIEIRA, M. B. The elements of representation in Hobbes: Aesthetics, theatre, law and theology in the construction of Hobbes's theory of State. Leiden \& Boston: Brill, 2009, pp. 15-16.
}

\begin{tabular}{|c|c|c|c|c|c|}
\hline intuitio & $\begin{array}{c}\text { ISSN } \\
1983-4012\end{array}$ & Porto Alegre & Vol.11 $-\mathrm{N}^{\circ} .2$ & $\begin{array}{c}\text { Dezembro } \\
2018\end{array}$ & p.34-46 \\
\hline
\end{tabular}


Art [i.e., visual representation] is for Hobbes a form of action. It produces its effects just as any other form of action does. In effect it has the potential to do so in an especially efficacious way, as it acts directly on what is, in Hobbes's view, the most important catalyst of human behaviour: passion as elicited by the imagination. (...) Images are invested with meaning by their makers. They do no merely mirror or stand in for the thing represented. They mould it. They construct it. They make claims for it. They very often generate the power of the things/persons they supposedly only represent ${ }^{3}$ (grifei).

Vieira afirma que, para Hobbes, a linguagem é potencialmente equívoca. As metáforas, diferentemente de expressões não-metafóricas, são, nesse sentido, menos fingidas - já que ao menos promovem o engodo abertamente, sendo "equivocal by profession". Em outras palavras, elas ao menos fazem jus ao caráter representacional da linguagem; em oposição a elas, as expressões não-metafóricas podem nos levar à falsa crença de que a linguagem corresponde a certa realidade pré-linguística, quando na verdade ela a representa arbitrariamente, construindo$a^{4}$.

Em uma interessante expressão, Vieira define a metáfora como "a sort of calculated mistake", em que tomamos uma coisa por outra, dando um nome a algo que pertence a outra coisa. Assim como a geometria (ciência que Hobbes tinha como modelo), as metáforas têm o poder de colocar uma imagem diante dos olhos do leitor-espectador, conferindo um caráter figurativo à mensagem. Elas nos desafiam, assim, a ir além do sentido literal de algo, sugerindonos aspectos desse algo que teriam passado despercebidos sem o recurso imagético. As metáforas consistem, portanto, na aplicação de um termo descritivo a determinado objeto que é diferente do objeto ao qual tal termo se refere comumente. Apesar dessa diferença, a aplicação da metáfora sugere precisamente uma analogia ou uma semelhança entre esses dois objetos. Nesse procedimento de transferir a um objeto um nome aplicável propriamente a outro algo, há o risco de que tomemos uma coisa pela outra, confundindo-as. Devido a essa tensão, inerente à metáfora, entre o real e o ficcional, Vieira afirma que, para compreender uma metáfora, é necessário ter

${ }^{3}$ VIEIRA, M. B. The elements of representation in Hobbes: Aesthetics, theatre, law and theology in the construction of Hobbes's theory of State. Leiden \& Boston: Brill, 2009, p. 17.

Sobre a importância das paixões, que será melhor trabalhada ainda neste texto, ver: HOBBES, T. Leviathan or the Matter, Forme and Power of a Commonwealth Ecclesiasticall and Civil, Oxford University Press, 1998, cap. 6 e nt. 10, infra. Sobre a imaginação e sua conexão com as ações: "It is evident, that the imagination is the first internal beginning of all voluntary motion" (p. 33).

${ }^{4}$ VIEIRA, M. B. The elements of representation in Hobbes: Aesthetics, theatre, law and theology in the construction of Hobbes's theory of State. Leiden \& Boston: Brill, 2009, pp. 53-54.

HOBBES, T. Leviathan or the Matter, Forme and Power of a Commonwealth Ecclesiasticall and Civil, Oxford University Press, 1998, pp. 46-47: "In demonstration, in counsel, and all rigorous search for truth, judgement does all (...). But for metaphors, they are in this case utterly excluded. For seeing they openly profess deceit" (grifei). No mesmo sentido, pp. 26-27.

\begin{tabular}{|c|c|c|c|c|c|}
\hline intuitio & $\begin{array}{c}\text { ISSN } \\
1983-4012\end{array}$ & Porto Alegre & Vol.11 - No.2 & $\begin{array}{c}\text { Dezembro } \\
2018\end{array}$ & p.34-46 \\
\hline
\end{tabular}


uma "visão dupla" - uma habilidade de enxergar algo, ao mesmo tempo, de pontos de vista distintos ${ }^{5}$ :

From the sensation initially caused by the metaphorical image, one must progress to the intelligible structure underlying it. As often happens in Hobbes's own texts, this can be captured in a paraphrase, which annuls the trope by restoring its proper meaning, as when the awing image of the biblical Leviathan (...) is paraphrased into "a Commonwealth, or State (in latine Civitas)", which is but a gigantic "Artificiall Man", representing the union of its subjects. Overpowering as an image, but absurd if taken literally, Leviathan is a metaphor inviting inspection ${ }^{6}$ (grifei).

\section{Inspecting Leviathan - um exame da metáfora introdutória do Leviathan}

Non est super terram potestas quae comparetur ei (HOBBES, frontispício do Leviathan, citando o livro de Jó) ${ }^{7}$.

No primeiro parágrafo do Leviathan, Hobbes recorre a uma metáfora para ilustrar a criação do Estado (Commonwealth, Civitas). A natureza é, segundo Hobbes, a arte por meio da qual Deus fez e governa o mundo. A arte do homem imita-a em muitas coisas, inclusive nesse ato de criação. Assim como Deus, por meio de sua arte (i.e., a natureza), criou o mundo, o homem é capaz de criar um animal artificial por meio de sua arte. Nesta primeira parte da metáfora, já se nota algo importante: o homem é comparado a Deus, na medida em que ambos, cada um por meio de sua respectiva arte, é capaz de um ato engenhoso de criação.

Continuando a metáfora, Hobbes vai explicar o que seria esse animal artificial que pode ser criado pelo homem. Nessa explicação, notamos a centralidade da noção de movimento para Hobbes. Segundo ele, a vida não é mais que o movimento das partes/membros (motion of limbs) - movimento este cujo início se encontra em alguma parte interna do corpo (neste ponto, Hobbes se refere, implicitamente, ao conceito de conatus ou endeavor, central para a sua definição de paixões). Fazendo uma breve digressão, cabe lembrar que, em Hobbes, o termo "paixões" não

\footnotetext{
${ }^{5}$ VIEIRA, M. B. The elements of representation in Hobbes: Aesthetics, theatre, law and theology in the construction of Hobbes's theory of State. Leiden \& Boston: Brill, 2009, pp. 54-56.

${ }^{6}$ VIEIRA, M. B. The elements of representation in Hobbes: Aesthetics, theatre, law and theology in the construction of Hobbes's theory of State. Leiden \& Boston: Brill, 2009, p. 57.

7 Na tradução de Ginzburg: "não existe poder sobre a terra comparável a ele". Cf.: GINZBURG, C. "Medo, reverência, terror: reler Hobbes hoje", trad. por Frederico Carotti, Joana Angélica d'Avila Melo e Júlio Castañonin. In: Medo, reverência, terror: quatro ensaios de iconografia política, Cia. Das Letras, 2014, pp. 20-21.
}

\begin{tabular}{|c|c|l|l|c|c|}
\hline intuitio & $\begin{array}{c}\text { ISSN } \\
1983-4012\end{array}$ & Porto Alegre & Vol.11- $\mathrm{N}^{\circ} .2$ & $\begin{array}{c}\text { Dezembro } \\
2018\end{array}$ & p.34-46 \\
\hline
\end{tabular}


tem a conotação negativa que tem comumente nos dias de hoje. Geralmente contrapostas à razão, as paixões são vistas atualmente como inferiores - a virtude consistindo em domá-las e reprimilas. Segundo Lebrun, esse não era o sentido original do termo (que deriva de pathos, paschein). Essa conotação negativa surgiu com o cristianismo, momento a partir do qual "esqueceu-se (...) de que a "virtude" pode ser determinada como simples questão de bom gosto e de equilíbrio das paixões em função das circunstâncias" ". Essa interpretação do termo se intensifica à medida que a razão ganha proeminência na filosofia, ao ponto de podermos concluir que "se a palavra paixão está solidamente associada à da repressão, é porque já representamos o logos como uma lei, expressa por um mandamento que se dirige a todos (...) [que] seriam capazes de a compreender pela mesma razão" ${ }^{9}$. Em Hobbes, não há essa conotação fortemente negativa ${ }^{10}$. Na interpretação de Limongi, a noção de conatus é central na concepção hobbesiana de paixão: do mesmo modo que, na física de Hobbes, essa noção explica o movimento (dispensando as noções de potencialidade e inclinação), ela assume a mesma função em sua teoria das paixões ${ }^{11}$. Em Hobbes, a paixão pode ser entendida como um "conteúdo cognitivo que envolve um juízo ou modo de conceber os objetos"12. A depender do conatus (endeavour) - de aproximação, ou de afastamento - que esse conteúdo cognitivo gera, falamos, respectivamente, em apetite ou aversão. O medo, por exemplo, conforme definido por Hobbes no capítulo VI do Leviathan, é "aversion with opinion of HURT from the object".

Feita essa pequena digressão sobre o modo como Hobbes entende o termo "paixão", retomemos a análise da metáfora inicial do Leviathan a partir de onde paramos — ou seja: a partir da definição de vida enquanto o movimento das partes/membros (motion of limbs). Sendo a vida o movimento das partes, por que não dizer que todos os automata (i.e., máquinas ou motores que se movem por meio de molas e rodas) têm uma vida artificial? Neste ponto é introduzida uma

\footnotetext{
${ }^{8}$ LEBRUN, G. "O conceito de paixão". In: NOVAES, A. (org.). Os sentidos da paixão. São Paulo: Cia das Letras, 2009, p. 16.

${ }^{9}$ LEBRUN, G. "O conceito de paixão". In: NOVAES, A. (org.). Os sentidos da paixão. São Paulo: Cia das Letras, 2009 , p. 21.

${ }^{10}$ Neste ponto, o que quero dizer é que, em Hobbes, não há a conotação negativa que Lebrun explicita no trecho citado no corpo do texto. Vide, por exemplo, o capítulo 6 do Leviathan, onde Hobbes trata mais detalhadamente das paixões. Nesse capítulo, já é possível notar que o tom utilizado para se referir às paixões não é depreciativo. Nele, Hobbes define uma série de paixões, explicando como elas surgem e como dão ensejo às ações voluntárias. HOBBES, T. Leviathan or the Matter, Forme and Power of a Commonwealth Ecclesiasticall and Civil, Oxford University Press, 1998, pp. 33-34 e p. 40.

${ }^{11}$ LIMONGI, M. I. "Hobbes e o conatus: da física à teoria das paixões". In? Discurso, n. 31, 9 dez. 2000, p. 433. Disponível em: <<http://www.revistas.usp.br/discurso/article/view/38048 〉>. Acessado em: 15/09/2018.

${ }^{12}$ LIMONGI, M. I. "Hobbes e o conatus: da física à teoria das paixões". In? Discurso, n. 31, 9 dez. 2000, p. 434. Disponível em: $<<$ http://www.revistas.usp.br/discurso/article/view/38048 $\gg$. Acessado em: 15/09/2018.
}

\begin{tabular}{|c|c|l|l|c|c|}
\hline intuitio & $\begin{array}{c}\text { ISSN } \\
1983-4012\end{array}$ & Porto Alegre & Vol.11- $\mathrm{N}^{\circ} .2$ & $\begin{array}{c}\text { Dezembro } \\
2018\end{array}$ & p.34-46 \\
\hline
\end{tabular}


comparação dentro da metáfora. Hobbes menciona o relógio como um exemplo de automata, dotado dessa vida artificial. Se, na primeira parte da metáfora, o homem foi comparado a Deus enquanto criador, nessa segunda parte a criação divina é comparada à humana. Diz Hobbes: o que é o coração, senão uma mola? Os nervos, senão cordas? As articulações, senão rodas que conferem movimento a todo o corpo, tal como intencionado pelo artífice? Essa comparação entre as partes do animal criado por Deus e as partes do animal artificial (i.e., os automata) criado pelo homem introduz dois elementos essenciais para o desenvolvimento da metáfora: o primeiro é a menção ao todo, ao "corpo" (giving motion to the whole body); e o segundo é a menção à intenção do criador ou artífice (such as was intended by the artificer).

Após mencionar esses dois elementos, Hobbes continua a metáfora, dizendo-nos que a arte humana vai além: ela é capaz de imitar a criação divina inclusive naquilo que Deus criou de mais excelente e racional - i.e., o homem. Isso porque por meio dela é criado o grande Leviatã, também chamado de Commonwealth ou Estado, que nada mais é senão um homem artificial. Neste ponto, a metáfora dá saltos importantes. Antes, vínhamos falando da criação divina no geral (i.e., sem fazer uma distinção entre o homem e os outros animais). A criação divina (i.e., os animais) era comparada à criação humana (i.e., as máquinas e motores). Enquanto os primeiros são dotados de vida, entendida como movimento das partes, estas, na medida em que suas partes se movimentam artificialmente, são dotadas de uma vida artificial. Nesse momento, porém, a metáfora é delimitada, ganhando um significado mais preciso. Isso porque a arte do homem é capaz de imitar a natureza (a arte divina) não só em suas criações "inferiores" (animais máquinas), mas também na sua mais excelente e racional criação. Esta, que no caso divino é o homem, no caso humano é o "homem artificial", o Leviatã. Por extensão, se o homem é a mais excelente e racional criação da natureza, o Leviatã é a mais excelente e racional criação do homem.

Como dito acima, tanto a menção ao "corpo" quanto à "intenção do artífice" são importantes na continuação da metáfora. Retomando esta segunda expressão, Hobbes nos diz que o Leviatã, entendido como homem artificial, diferencia-se do homem natural por ser de maior estatura e força (faria isso ser a criação humana superior à criação divina?), e tem como propósito a proteção e a defesa deste. O homem enquanto artífice, portanto, tem como intenção, ao criar o Leviatã, sua própria defesa e proteção - ponto central na filosofia política de Hobbes. Retomando o termo "corpo", Hobbes afirma que a soberania dá vida e movimento ao corpo artificial do

\begin{tabular}{|c|c|l|l|c|c|}
\hline intuitio & $\begin{array}{c}\text { ISSN } \\
1983-4012\end{array}$ & Porto Alegre & Vol.11- $\mathrm{N}^{\circ} .2$ & $\begin{array}{c}\text { Dezembro } \\
2018\end{array}$ & p.34-46 \\
\hline
\end{tabular}


Leviatã, assim como a alma o faz em relação ao corpo humano. A partir de então, Hobbes, do mesmo modo que tinha comparado as partes do animal às partes das máquinas e motores, compara as partes do corpo do homem artificial (i.e., do Leviatã) às partes do corpo do homem natural. A soberania, como dito, é como uma alma artificial; as recompensas e punições, como os nervos; as riquezas, como a força; a segurança do povo, como seu objetivo (business); os conselheiros, como a memória; as leis e a equidade são como uma razão e uma vontade artificiais; a concórdia é como a saúde; a sedição, como a doença; e a guerra civil, como a morte. Nessas comparações, destaca-se sobretudo esta última. Se a morte é a ruína do homem natural, a guerra civil seria a ruína do Estado. Daí já se depreende outro traço marcante da filosofia política hobbesiana: sua preocupação em evitar a guerra civil, já que esta é entendida como a morte do corpo político.

Terminando a metáfora, Hobbes faz referência ao ato de criação e, assim, a outro elemento central de sua filosofia política: aos pactos e tratados (pacts and covenants). Estes são os atos por meio dos quais as partes do corpo político foram criadas, e, nesse sentido, comparamse ao comando criador divino (“que se faça o homem!"). Disso depreende-se a centralidade dos pactos no pensamento político de Hobbes, já que é por meio deles que o homem, comparado a Deus, comanda a criação do Leviatã; é por meio deles que profere "que se faça o homem artificial!" - sua mais excelente e racional criação.

\section{Inspecting Leviathan - "Awe" e a semelhança entre o Leviatã e a religião}

O medo e eu somos gêmeos ${ }^{13}$.

Em seu ensaio Medo, reverência, terror: reler Hobbes hoje, Ginzburg baseia sua análise na noção de Pathosformeln ("fórmulas de emoções"). O autor não dá uma definição precisa do que entende pelo termo, mas o explica por meio de um exemplo citando o diário de Darwin: “É curioso observar, e certamente é verdade, que os extremos de paixões opostas são expressos com pouquíssima variação pela mesma ação. (...) Ele [Joshua Reynolds] dá como exemplo a alegria

${ }^{13}$ HOBBES, apud GINZBURG, C. "Medo, reverência, terror: reler Hobbes hoje", trad. por Frederico Carotti, Joana Angélica d'Avila Melo e Júlio Castañonin. In: Medo, reverência, terror: quatro ensaios de iconografia política, Cia. Das Letras, 2014, p. 19.

\begin{tabular}{|c|c|l|l|c|c|}
\hline intuitio & $\begin{array}{c}\text { ISSN } \\
1983-4012\end{array}$ & Porto Alegre & Vol.11- $\mathrm{N}^{\circ} .2$ & $\begin{array}{c}\text { Dezembro } \\
2018\end{array}$ & p.34-46 \\
\hline
\end{tabular}


frenética de uma bacante e a dor de uma Maria Madalena"14. Ginzburg diz que nessa citação temos os dois principais elementos da noção de Pathosformeln: sua relação com a Antiguidade, e a inversão de emoções. Essa noção, proposta por Aby Warburg, estava bastante presente na arte renascentista, que retomava gestos de emoção extraídos da Antiguidade - porém com seu significado invertido. É com base nessa noção que Ginzburg pretende analisar o termo awe na obra de Hobbes, termo ambivalente em que se expressam duas emoções extremas: horror e veneração $^{15}$.

Apesar de a noção de Pathosformeln ter se voltado originalmente a iluminar as raízes antigas de imagens modernas (e o modo pelo qual elas foram reelaboradas), Ginzburg diz que tal noção pode ser aplicada também a outros fenômenos, dando como exemplo a imagem contida no frontispício do Leviathan. Segundo ele, essa imagem traduz de maneira inovadora a frase de Tácito "acreditam naquilo que acabaram de criar". Nesse caso, porém, continua Ginzburg, estamos diante de uma "fórmula do conhecer" (Logosformel), na medida em que somos dominados por mentiras por nós mesmos criadas ${ }^{16}$. Isso não significa, porém, que a imagem do frontispício não alcança as emoções; muito pelo contrário: ela certamente expressa de maneira bastante emblemática o termo awe e sua ambivalência. Como nos lembra Ginzburg, o medo está no centro da filosofia política hobbesiana. Todavia, a noção de medo tem importância central não só nesta, mas também na análise de Hobbes sobre a religião. O Leviatã, imagem empregada para se referir ao Estado, tem sua origem na bíblia (mais precisamente, no livro de Jó) e diz respeito a uma baleia gigante. No frontispício de seu livro, Hobbes cita em latim um versículo do livro de Jó: non est super terram potestas quae comparetur ei, que pode ser traduzido como "não existe poder sobre a terra comparável a ele" ${ }^{17}$. No capítulo 12 - "Of Religion" - do Leviathan, Hobbes afirma que a ansiedade e o medo estão na base da religião. O desejo de conhecer as causas das coisas gera no homem uma ansiedade em relação ao futuro, o que o faz temer o poder das coisas

${ }^{14}$ GINZBURG, C. "Medo, reverência, terror: reler Hobbes hoje", trad. por Frederico Carotti, Joana Angélica d'Avila Melo e Júlio Castañonin. In: Medo, reverência, terror: quatro ensaios de iconografia política, Cia. Das Letras, 2014, p. 10.

${ }^{15}$ GINZBURG, C. "Medo, reverência, terror: reler Hobbes hoje", trad. por Frederico Carotti, Joana Angélica d'Avila Melo e Júlio Castañonin. In: Medo, reverência, terror: quatro ensaios de iconografia política, Cia. Das Letras, 2014, pp. 5, 8, 10, 11-13.

${ }^{16}$ GINZBURG, C. "Medo, reverência, terror: reler Hobbes hoje", trad. por Frederico Carotti, Joana Angélica d'Avila Melo e Júlio Castañonin. In: Medo, reverência, terror: quatro ensaios de iconografia política, Cia. Das Letras, 2014, pp. 13-14.

${ }^{17}$ GINZBURG, C. "Medo, reverência, terror: reler Hobbes hoje", trad. por Frederico Carotti, Joana Angélica d'Avila Melo e Júlio Castañonin. In: Medo, reverência, terror: quatro ensaios de iconografia política, Cia. Das Letras, 2014, pp. 20-21.

\begin{tabular}{|c|c|c|c|c|c|}
\hline intuitio & $\begin{array}{c}\text { ISSN } \\
1983-4012\end{array}$ & Porto Alegre & Vol.11 $-\mathrm{N}^{\circ} .2$ & $\begin{array}{c}\text { Dezembro } \\
2018\end{array}$ & p.34-46 \\
\hline
\end{tabular}


invisíveis. A religião tem, assim, a ansiedade em relação ao futuro como causa natural. Seria o Estado-Leviatã uma espécie de religião-Deus que aplaca o medo do homem?

Não ignoramos que Hobbes visa combater as origens desses medos falsos gerados pela ignorância e imaginação humanas (e, consequentemente, descreditar as religiões pagãs ${ }^{18}$ ). Sendo assim, antes de responder à questão do parágrafo anterior, caberia considerar a pergunta a respeito de se essa desmistificação não afetaria também o Estado (na figura do Leviatã). Essa questão surge, por exemplo, após a leitura do seguinte trecho de Vieira:

This is an exercise in demystification that Hobbes thinks heavy with political implications. Where man's eyes are taught to see through the deceptions to which vision is naturally subject, the manipulation of opinion through the manipulation of visual appearances is made more difficult, and men fitter for obedience to the only icon deserving their reverence: the image of their collective being as personified by the Leviathan state ${ }^{19}$.

Se Hobbes planejava revelar os truques por meio dos quais se manipulava a opinião por meio do visual, por que recorrer à poderosa metáfora visual do Leviatã enquanto imagem do ser político coletivo? Não seriam essas atitudes contraditórias? Em que medida a desmistificação feita por Hobbes das religiões pagãs não afetariam também seu artifício metafórico-visual do Leviatã? De acordo com Vieira, esse problema poderia se resolver por meio de uma distinção entre dois tipos de uso da representação visual. O uso condenado e desmascarado por Hobbes seria apenas aquele que esconde seu caráter representacional com o intuito de que se confunda a representação com o real. Esse primeiro tipo seria o empregado por clérigos para manipular os homens. Há, porém, um segundo tipo de uso, no qual o caráter representacional é professado abertamente, e em que o espectador é chamado a cooperar na produção do efeito da imagem. Esse seria, segundo Vieira, o modo por meio do qual Hobbes empregara a representação visual ${ }^{20}$. Isso resolve a questão posta? Parece-me que não. Isso porque há uma tendência natural nos homens de tomar a representação por algo real, destacada pelo próprio Hobbes quando menciona,

\footnotetext{
${ }^{18}$ Em que medida esse combate mina não só as religiões pagãs, mas também a "verdadeira religião" é uma questão interessante, mas que não será aqui enfrentada. Limitamo-nos a registrar que Hobbes faz questão de frisar explicitamente que seus ataques não atingem a "verdadeira religião". Seu texto, porém, dá margem para que interpretamos o contrário.

19 VIEIRA, M. B. The elements of representation in Hobbes: Aesthetics, theatre, law and theology in the construction of Hobbes's theory of State. Leiden \& Boston: Brill, 2009, p. 18.

20 VIEIRA, M. B. The elements of representation in Hobbes: Aesthetics, theatre, law and theology in the construction of Hobbes's theory of State. Leiden \& Boston: Brill, 2009, pp. 71-72.
}

\begin{tabular}{|c|c|l|l|c|c|}
\hline intuitio & $\begin{array}{c}\text { ISSN } \\
1983-4012\end{array}$ & Porto Alegre & Vol.11- No.2 & $\begin{array}{c}\text { Dezembro } \\
2018\end{array}$ & p.34-46 \\
\hline
\end{tabular}


no Leviathan, exemplos de adoração de imagens e estátuas ${ }^{21}$. Nesse caso, mesmo que o artistaorador não esconda o caráter representacional de sua imagem, há tendência para a confusão. Se, dada essa tendência, os dois modos de uso da representação visual tendem a convergir, o ataque de Hobbes poderia acabar afetando tanto a representação visual a que recorrem os clérigos, quanto a representação visual a que ele próprio recorre.

Apesar disso, o medo, como dissemos, não deixa de ser elemento central - não só como uma paixão que leva à religião, mas também como a base da origem do Estado. Tanto neste quanto naquela, uma explicação de sua origem pelo medo se faz presente. Em ambos, o termo awe tem importância central. No caso da religião, os medos e ansiedades de que falamos fazem com que os homens se deixem levar por sua imaginação, encarando com sujeição (awe) o que imaginam $^{22}$. No caso do Estado-Leviatã, o mesmo termo surge para caracterizar a condição de guerra de todos contra todos - que ocorre durante o período de tempo em que os homens vivem sem um poder comum que os mantenha em um estado de sujeição (keep them all in awe) ${ }^{23}$. Ginzburg chama a atenção para esse paralelo, dizendo que: "seja no caso da origem da religião, seja no da origem do Estado, encontramos no início o medo (feare) e, no fim, como resultado, a sujeição ou reverência (awe). No meio, a ficção, que se impõe àqueles que a criaram como uma realidade" 24 . A ficção a que ele se refere designa, num caso, a própria religião, e, no outro, os pactos e o Estado-Leviatã deles originário. Ambos surgem do medo; ambos levam à sujeição, à reverência.

Ginzburg lembra ainda uma passagem do próprio Leviathan que, de certa forma, permitenos responder afirmativamente à nossa questão: "This is the generation of that great LEVIATHAN, or rather (to speake more reverently) of that Mortall God, to which wee owe under the Immortal God, our peace and defence" ${ }^{25}$. O Estado-Leviatã é, de certa forma, uma religião-Deus que surge, em parte, do medo do homem; assim como a religião, o Leviatã aplaca

${ }^{21}$ HOBBES, T. Leviathan or the Matter, Forme and Power of a Commonwealth Ecclesiasticall and Civil, Oxford University Press, 1998, cap. 45, pp. 437-38.

${ }^{22}$ GINZBURG, C. "Medo, reverência, terror: reler Hobbes hoje", trad. por Frederico Carotti, Joana Angélica d'Avila Melo e Júlio Castañonin. In: Medo, reverência, terror: quatro ensaios de iconografia política, Cia. Das Letras, 2014, pp. 35-36.

${ }^{23}$ HOBBES, T. Leviathan or the Matter, Forme and Power of a Commonwealth Ecclesiasticall and Civil, Oxford University Press, 1998, cap. 13, 8.

${ }^{24}$ GINZBURG, C. "Medo, reverência, terror: reler Hobbes hoje", trad. por Frederico Carotti, Joana Angélica d'Avila Melo e Júlio Castañonin. In: Medo, reverência, terror: quatro ensaios de iconografia política, Cia. Das Letras, 2014, pp. 35-38 e 42.

${ }^{25}$ HOBBES, T. Leviathan or the Matter, Forme and Power of a Commonwealth Ecclesiasticall and Civil, Oxford University Press, 1998, cap. 17.

\begin{tabular}{|c|c|l|l|c|c|}
\hline intuitio & $\begin{array}{c}\text { ISSN } \\
1983-4012\end{array}$ & Porto Alegre & Vol.11- $\mathrm{N}^{\circ} .2$ & $\begin{array}{c}\text { Dezembro } \\
2018\end{array}$ & p.34-46 \\
\hline
\end{tabular}


esse medo ao mesmo tempo em que inspira no homem reverência e sujeição. Na verdade, é essa própria reverência e sujeição que remediam o medo e a ansiedade em relação ao futuro que abalam o homem. No caso das religiões, tal remediação se dá por meio da crença de que as divindades têm poderes sobrenaturais, de modo que, se devidamente cultuadas, favorecerão e protegerão os homens. No caso do Estado-Leviatã, por meio do próprio pacto que o cria, na medida em que os homens renunciam à sua disposição de resolver suas contendas por meio da guerra. Como lembra Hobbes, "[W]ar consisteth not in battle only, or the act of fighting; but in a tract of time, wherein the will to contend by battle is sufficiently known"26. Os pactos comparados por Hobbes ao comando divino de criação do homem - e o Estado-Leviatã por eles criado são a segurança ou a garantia de que os homens não resolverão suas desavenças por meio da guerra, pondo fim, assim, à condição de medo contínuo e de perigo de morte violenta que caracteriza a vida do homem na ausência desse poder comum.

$\mathrm{Na}$ interpretação de Ginzburg, esse paralelo ganha ainda uma dimensão mais profunda. Para ele, o Estado pressupõe a força (representada pela espada no frontispício do livro), mas esta apenas não basta. Além dela, são necessárias a sujeição e a reverência inspiradas pelo EstadoLeviatã enquanto "Deus mortal" gerado pelo medo. Essa mistura inextricável entre medo e sujeição - já observada nas religiões, e representada no frontispício pelo báculo (cajado sagrado) - é também essencial para que o Estado se apresente como autoridade legítima ${ }^{27}$. A figura do Leviatã e sua representação evocam, assim, a "terrível ambivalência do sagrado" 28 , indicando-nos a proximidade entre os fenômenos religioso e político.

\section{Conclusão}

Este pequeno ensaio se dividiu em três seções principais. Na primeira delas, retomamos trechos do livro The elements of representation in Hobbes, de Mónica Vieira, com o intuito de introduzir nosso tema: o Leviatã enquanto metáfora e representação. Ressaltamos a importância,

\footnotetext{
${ }^{26}$ HOBBES, T. Leviathan or the Matter, Forme and Power of a Commonwealth Ecclesiasticall and Civil, Oxford University Press, 1998, cap. 13, 8.

${ }^{27}$ GINZBURG, C. "Medo, reverência, terror: reler Hobbes hoje", trad. por Frederico Carotti, Joana Angélica d'Avila Melo e Júlio Castañonin. In: Medo, reverência, terror: quatro ensaios de iconografia política, Cia. Das Letras, 2014, pp. 42-45.

${ }^{28}$ GINZBURG, C. "Medo, reverência, terror: reler Hobbes hoje", trad. por Frederico Carotti, Joana Angélica d'Avila Melo e Júlio Castañonin. In: Medo, reverência, terror: quatro ensaios de iconografia política, Cia. Das Letras, 2014, p. 47.
}

\begin{tabular}{|c|c|l|l|c|c|}
\hline intuitio & $\begin{array}{c}\text { ISSN } \\
1983-4012\end{array}$ & Porto Alegre & Vol.11- $\mathrm{N}^{\circ} .2$ & $\begin{array}{c}\text { Dezembro } \\
2018\end{array}$ & p.34-46 \\
\hline
\end{tabular}


resgatada por Vieira, do elemento estético da teoria da representação em Hobbes, chamando a atenção para o componente estético da metáfora que introduz o Estado (Commonwealth) já no primeiro parágrafo do Leviathan. Com base em Vieira, defendemos que, para Hobbes, as imagens não são representações passivas do representado, mas ativas - já que acabam por moldar e construir aquilo que visam representar, sendo a imagem do Leviatã, mobilizada por Hobbes, um bom exemplo disso. Feito isso, ainda na primeira seção, destacamos o caráter equívoco da metáfora. Devido a tal caráter, quando uma metáfora é empregada, há sempre uma tensão entre o real e o ficcional. Concluímos a seção com uma citação que é, ao mesmo tempo, um convite: Leviathan as a metaphor inviting inspection. Nas seções 2 e 3, aceitamos o convite.

$\mathrm{Na}$ seção 2, procuramos reconstruir a metáfora do Leviatã conforme apresentada por Hobbes já no primeiro parágrafo de seu livro; ao fazer isso, procuramos também analisá-la, buscando os significados sugeridos pelo texto. Já no começo da metáfora, notamos que o homem é comparado a Deus, na medida em que ambos, cada um por meio de sua respectiva arte, é capaz de um ato engenhoso de criação: o mundo, no caso de Deus, e um animal artificial (automata), no caso do homem. Hobbes procede, então, à comparação entre as criações divina e humana, chegando à conclusão de que a arte humana consegue imitar a arte divina até mesmo naquilo que nela é mais excelente e racional (i.e., o próprio homem). Isso é feito por meio da criação do Leviatã, o "homem artificial" — que é, assim, a mais excelente e racional criação do homem. Este é mais mais fraco e de menor estrutura do que o "homem artificial". Neste ponto, ressaltamos três traços importantes da filosofia política de Hobbes que já ficam nítidos no desenvolvimento dessa metáfora. Primeiro, a centralidade das noções de defesa e proteção para o homem natural (sua intenção ao criar o Leviatã era a de assegurar sua própria proteção e defesa). Segundo, a preocupação de Hobbes em evitar a guerra civil, na medida em que esta é entendida como a própria morte do corpo político. A morte, que no caso do homem natural representa sua ruína, seria equivalente à guerra civil, que representa a ruína do Estado-Leviatã. Por fim, a importância dos pactos e tratados, que são os atos por meio dos quais as partes do corpo político foram criadas.

Na seção 3, com base em um ensaio de Ginzburg, exploramos outra dimensão do Leviatã enquanto metáfora: a semelhança entre o Leviatã e a religião. Para tanto, retomamos a noção de Pathosformeln e o modo como ela foi empregada por Ginzburg para analisar o termo awe na obra de Hobbes. A imagem do Leviatã expressa de maneira bastante simbólica a ambivalência do

\begin{tabular}{|c|c|c|c|c|c|}
\hline intuitio & $\begin{array}{c}\text { ISSN } \\
1983-4012\end{array}$ & Porto Alegre & Vol.11- No.2 & $\begin{array}{c}\text { Dezembro } \\
2018\end{array}$ & p.34-46 \\
\hline
\end{tabular}


termo awe, que denota, ao mesmo tempo, horror/medo e veneração/reverência. Argumentamos que essas paixões têm papel central não só no fenômeno político (representado pela imagem do Leviatã), mas também no fenômeno religioso. Mais especificamente, mostramos que o medo está na base tanto na origem da religião, quanto na origem do Estado. A reverência, por sua vez, surge como resultado de ambos os fenômenos. Estado e religião: ambos surgem do medo; ambos levam à reverência. Diante disso, perguntamo-nos se o Estado-Leviatã seria uma espécie de religiãoDeus que aplaca o medo do homem. A questão foi respondida afirmativamente, com base em trechos de Hobbes (em que este equipara o Leviatã a um Deus Mortal), bem como em uma análise mais detida da semelhança entre os fenômenos religioso e político em Hobbes. Concluímos a seção destacando a mistura inextricável entre medo e sujeição — tão bem denotada pelo termo awe: a importância central que ela tem na figura do Leviatã e em sua representação indicam a proximidade entre o político e o sagrado.

\section{Bibliografia}

GINZBURG, C. "Medo, reverência, terror: reler Hobbes hoje", trad. por Frederico Carotti, Joana Angélica d'Avila Melo e Júlio Castañonin. In: Medo, reverência, terror: quatro ensaios de iconografia política, Cia. Das Letras, 2014, pp. 14-46.

HOBBES, T. Leviathan or the Matter, Forme and Power of a Commonwealth Ecclesiasticall and Civil, Oxford University Press, 1998.

LEBRUN, G. "O conceito de paixão". In: NOVAES, A. (org.). Os sentidos da paixão. São Paulo: Cia das Letras, 2009, pp. 12-32.

LIMONGI, M. I. "Hobbes e o conatus: da física à teoria das paixões". In? Discurso, n. 31, pp. 417-440, 9 dez. 2000. Disponível em: <http://www.revistas.usp.br/discurso/article/view/38048 >. Acessado em: 15/09/2018.

VIEIRA, M. B. The elements of representation in Hobbes: Aesthetics, theatre, law and theology in the construction of Hobbes's theory of State. Leiden \& Boston: Brill, 2009.

\begin{tabular}{|c|c|c|c|c|c|}
\hline intuitio & $\begin{array}{c}\text { ISSN } \\
1983-4012\end{array}$ & Porto Alegre & Vol.11 - No.2 & $\begin{array}{c}\text { Dezembro } \\
2018\end{array}$ & p.34-46 \\
\hline
\end{tabular}

